\title{
O DIREITO DO TRABALHO E O SÉCULO XXI
}

\author{
Octavio Bueno Magano \\ Professor Titular aposentado do Departamento de Direito do \\ Trabalho da Faculdade de Direito da Universidade de São Paulo
}

\section{Resumo:}

Por mediar de hoje, quase dois anos até o início do século XXI (2001), haverá tempo suficiente para a adaptação do Direito do Trabalho brasileiro, ainda marcado pelo nacionalismo corporativista dos anos 30 , às exigências da globalização, que, a partir do novo marco temporal, far-se-ão sentir, de modo mais acentuado. As principais características do fenômeno em causa são a interpenetração de mercados, as novas tecnologias, a homogeneização das preferências dos consumidores, a estandardização dos métodos de produção e a produção em escala globalizante. Diante do exposto, conclui-se que, ao invés de continuarem os povos na concha do nacionalismo, devem, ao contrário, buscar a expansão, através da participação em conglomerados internacionais. Entre os conglomerados atualmente existentes, realça-se o Mercosul, resultante do Tratado de Assunção, de 26.03.90, subscrito pela Argentina, Brasil, Paraguai e Uruguai e robustecido pelo Protocolo de Ouro Preto, de 17.12.94, que lhe atribuiu personalidade internacional. $\mathrm{Na}$ área trabalhista, o Mercosul estabelece, como finalidade, a lograr a harmonização de institutos jurídicos. Para muitos autores, tal objetivo se alcançaria com a adoção do maior número possível de Convenções da OIT e com a edição de uma Carta Social. Já o autor deste artigo entende que o mesmo objetivo deve ser buscado não através de benefícios outorgados por entidades estatais, mas por meio de condições negociadas, através de contratação coletiva de âmbito supranacional.

\section{Abstract:}

As there are now dose to two years before the beginning of the XXIst C. (2001), there will be sufficient time for adaptation of the Brazilian Labour Law, still marked by the nationalistic corporativism of the thirties, to the demands of globalization, which will become increasingly pronounced as the new era unfolds. The main characteristics of the phenomenon in question, as generally viewed, are the interpenetration of markets, the generic nature of the new information technologies, the accelerated homogenization of consumer tastes, product standards, and production methods on a global scale. In view of such, it may be concluded that instead of people continuing to remain within their nationalistic shells, they must, on the contrary, look towards expansion through participation in international conglomerates. Amongst existing conglomerates, Mercosul comes to the fore, as a result of the Asuncion Treaty, subscribed by Argentina, Brazil, Paraguay and Uruguay. Within the labour ambit, Mercosul's aim is to achieve harmony of juridical 
institutions. For many authors such an objective would be reached with the adoption of as many conventions as possible of the ILO, and with the edition of a Social Chart. The author of the article herewith resumed, however, understands that the same objective must be reached not through the conceding of benefits by State entities, but rather through conditions negotiated via collective contracting within a supra national area.

Unitermos: conglomerados internacionais; Nafta; Mercosul.

\section{Introdução}

Antes de mais nada, cumpre assinalar que, ao contrário do que freqüentemente se supõe, o século XXI iniciar-se-á não em $1^{\circ}$ de janeiro de $2000 \mathrm{e}$ sim em $1^{\circ}$ de janeiro de 2001.

Como se lê em Caldas Aulete, século é "espaço de cem anos, contados de um até cem desde um termo fixo chamado era (isto é, de 101 a 200, de 201 a 300 e assim por diante)." Para o Dicionário Larousse século constitui "espace de cent ans numérotés de 1 à 100 , de 101 à 200, de 201 à 300, etc., en partant d'un terme fixe appelé ère" I Não destoam daí os esclarecimentos contidos no "Standard Dictionary": "A period of 100 years in any system of chronology, especially in reckoning from the first year of the Christian era: The Twentieth Century A.D. $1901-2000^{\prime \prime} 2$

Decorre do exposto, existir ainda praticamente dois anos para se acertar o passo do Direito do Trabalho brasileiro com o estereótipo que haverá de prevalecer a partir do século XXI.

O modelo em causa encontra-se ligado ao fenômeno da globalização, tal como vem de ser sublinhado por Fernando Henrique Cardoso, ao ensejo de sua posse para cumprimento de um segundo mandato presidencial, "verbis": "Em um sistema internacional, em que aumenta a interdependência, é inevitável que sejamos afetados por eventos originados em outras regiões do mundo, mesmo as mais longínquas. 3

1. Noveau Larousse Illustré, Paris, ed. Larousse, t. VII, p. 688.

2. Nova York, Funk and Wagnalls, 1970, p. 217.

3. O Estado de S. Paulo, de 02/01/99, p. A-5. 
Não é, aliás, a primeira vez que o presidente da República trata do assunto. Já o fizera antes, de modo mais desenvolto, nestes termos: "A revolução contemporânea alcança além da cadeia de produção, e extingue o 'fordismo' e o 'taylorismo', revoluciona a organização da fábrica e da gerência; atinge o setor público, as escolas, igrejas, sindicatos e, por fim, o todo não-somente através de novos métodos de gerenciamento que passa a permitir, mas também através da criação de grandes redes de comunicação de massa; não-somente através dos meios de comunicação eletrônicos convencionais (rádio e televisão), mas também através das redes de computadores, máquinas de fac-símile, modems, e tudo o mais. Tudo isso, somado (e por ela tornado possível) a proliferação das grandes firmas manufatureiras, bancos e companhias comerciais, formam as bases de uma economia globalizada. E, portanto, juntamente com o casamento da ciência, tecnologia e liberdade, a grande tendência do mundo moderno é a globalização da economia". 4

Se a tendência do mundo moderno é a globalização da economia, o que significa, em síntese, atividade econômica exercida em âmbito internacional, mostra-se claro que o Brasil não pode continuar jungido à sistema de nacionalismo corporativista, como o que aqui se instaurou na década dos anos 30 e que continua a prevalecer até os dias atuais.

O regime de que se trata foi formalmente implantado em nosso País, a partir da Carta Constitucional de 10 de novembro de 1937, inspirada na "Carta del Lavoro" italiana, de 21 de abril de 1927, cujo escopo era a implantação de um Estado nacionalista corporativista. ${ }^{5}$

Tal modelo que, na área trabalhista, continuou praticamente intacto, apesar do advento das sucessivas Constituições de 1946, 1967, 1969 e 1988, mostrase incompatível com as feições do mundo globalizado.

Para demonstrá-lo, convém, inicialmente, trazer à tona quais sejam as apontadas características.

Como acentuam Werner Sengenberger e Frank Wilkinson, "it is generally recognized that the interpenetration of markets, the generic nature of the new information technologies, the accelered homogenization of consumer tastes,

4. Relações Norte-Sul no Contexto Atual: Uma Nova Dependência, in O Brasil e a Economia Global, organizador Baumann, Renato, Rio de Janeiro, SOBEET, 1996, p. 10.

5. Carocci, Giampero, Storic del Fascimo, Roma, Newton Compton editori, 1994, pp. 30-42. 
product standards, and production methods on a global scale, and mergers and acquisitions (which) are leading to worldwide economic restructuring leaving large corporations less dependent on any one nation's economy'. 6

Diante de tais fatores, o risco do colapso das economias presas ao modelo nacionalista é muito grande. Ainda na trilha dos autores citados, pode-se dizer que "national governments and national labour organizations lose their regulative power over economic behaviour within their borders. 7

A estratégia a se adotar a fim de se evitarem os indigitados inconvenientes é a da redução de custos, a da especialização das linhas de produção, a de estabilidade e controle de qualidade crescente na oferta de bens e serviços. ${ }^{8}$ Ao invés de se aninharem os povos na concha do nacionalismo, devem, ao contrário, buscar a expansão, através da participação em conglomerados internacionais. ${ }^{9}$

\section{Conglomerados Internacionais}

Os conglomerados internacionais, atualmente existentes, são os seguintes: a. Comunidade Européia, integrada pela França, Itália, Alemanha, Inglaterra, Espanha, Portugal, Bélgica, Grécia, Países Baixos, Dinamarca, Irlanda e Luxemburgo, Finlândia, Áustria e Suécia; b. Nafta (North American Free Trade Agreement), formado pelos EUA, Canadá e México; c. CEI (Comunidade de Estados Independentes), constituída pela Rússia, Bielorússia, Moldávia e Azerbaijão; d. União Econômica dos Estados Árabes, de que fazem parte Arábia

6. Globalization and Labour Standards in Managing the Global Economy, coordenado por Michie, Jonathan e Grieve, John, Nova York, Oxford University Press, 1995, p. 113.

7. Idem, p. 111 .

8. Baumann, Renato, Uma Visão Econômica da Globalização, in ob. cit., "O Brasil e a ...", p. 44.

9. Baumann, Renato, Uma Visão Econômica da Globalização, in ob. cit., "O Brasil e a ...", p. 44. Héctor-Hugo Barbagelata entende que "la integración económica puede tender consecuencias beneficiosas y negativas'. (Exploración preliminar de la proyectada integración en el Mercosur desde la perspectiva laboral, in Debate Laboral Revista Americana e Italiana de Derecho del Trabajo, San José, Laser S.A., ano IV, n. 8-9/1991, p. 7). Tratando dos aspectos negativos de integração María Carmen Ferreira e Julio Ramos Oliveira assim se expressam: "La primera perturbación a nível de empresa, que se cita generalmente como desfavorable, es la competencia desencadenada entre los socios comunitarios, que prejudique los niveles de empleo. Se teme que ciertos países o ciertas regiones mantengan adrede un bajo nivel social o salarial, y no se encuentren dispuestos a revisarlos hacia arriba para asi atraer a inversiones, poniendo en peligro los puestos de trabajo ya existentes en otras regiones". Mercosul Enfoque Laboral, Montevideo, Fundacion de Cultura Universitaria, 1991 p. 51 . 
Saudita, Iraque, Jordânia, Kuwait, Líbano, Marrocos, República Árabe Unida, Síria, Sudão, Tunísia e Iêmen; e. União Econômica da África Central, compreendendo Chade, Congo, Gabão e República Centro-Africana; f. Caricom (Mercado Comum do Caribe), cujos membros fundadores são Barbados, Guiana, Jamaica e TrinidadTobago; g. Pacto Andino, jungindo Bolívia, Equador, Peru e Venezuela; h. ANSEA (Associação das Nações do Sudeste Asiático), englobando os países da região referidos em sua denominação; i. APEC (Asia-Pacific Economic Cooperations), integrada por dezenove economias de países com frente para o Oceano Pacífico; j. Mercosul (Mercado Comum do Sul), composto pela Argentina, Brasil, Paraguai e Uruguai.

Os conglomerados implicam diferentes graus de integração, consoante a seguinte ordem.

Primeiro, a zona de livre comércio, ou seja, aquela em que se suprimem os obstáculos à livre circulação de bens e serviços. Em segundo lugar, a união aduaneira, que supõe, ademais, tarifa externa comum. ${ }^{10}$ Em terceiro lugar, o mercado comum, que constitui o espaço sem fronteiras internas, no qual se assegura a livre circulação de mercadorias, pessoas, serviços e capitais. Em quarto lugar, a comunidade econômica, que exterioriza a unificação da política macroeconômica dos Estados-Membros. Por último, a união monetária, que se caracteriza pela utilização da mesma unidade monetária em todos os Estados que a compõem.

Entre os conglomerados, acima alinhados, os mais significativos para o Brasil são o Mercosul, a União Européia e o Nafta. Cumpre, por isso, que se ofereçam aqui maiores esclarecimentos sobre as respectivas estruturas e funcionamento, deixando-se que os relacionados com o Mercosul venham por último, dadas as conseqüências de ser ele integrado pelo Brasil.

10. Ari Possidonio Beltran distingue a união aduaneira da união tarifária, assim se exprimindo: "União aduaneira não deixa de ser uma união tarifária, com a qual, contudo, não se confunde, porquanto a união aduaneira é modalidade mais aperfeiçoada. Segundo os autores, uma verdadeira união aduaneira supõe que o produto total das tarifas externas percebidas por todas as alfândegas que fiscalizam o ingresso ou saída de mercadorias do território aduaneiro da Comunidade, seja atribuido a um caixa comum e repartido entre os fiscos dos países membros" (Os impactos da integração econônica no Direito do Trabalho: globalização e direitos sociais, São Paulo, LTr, 1998, p. 42). 


\section{Comunidade Européia}

Sucintamente há de se indicar, como marco inicial de sua origem, o Tratado de Paris, de 18 de abril de 1951, gerador da Comunidade Européia do Carvão e do Aço (CECA). Seis anos depois se subscreveram, em Roma, dois Tratados instituidores, respectivamente, da Comunidade Européia para a Energia Atômica (CEEA), também denominada EURATOM, e a Comunidade Econômica Européia. Seguem-se o Ato Único Europeu, subscrito em fevereiro de 1986, e, finalmente, em 7 de fevereiro de 1992, o Tratado de Maastricht, subscrito, então, pelos seguintes países: França, Inglaterra, Irlanda, Bélgica, Holanda, Luxemburgo, Alemanha, Dinamarca, Itália, Grécia, Espanha e Portugal. Seu objetivo primacial consiste na "promoção de um processo econômico e social equilibrado e sustentável, nomeadamente mediante a criação de um espaço sem fronteiras internas e o reforço da coesão econômica e social e o estabelecimento de uma União Econômica e Monetária, que incluirá, a prazo, a adoção de uma moeda única ... (vide Título I, arts. A e B).

Em conformidade com essa parte final do referido Tratado, no dia 4 de janeiro último, passou a ter voga a moeda chamada Euro, destinada a prevalecer entre os países da Comunidade Européia, com exceção da Inglaterra, Suécia, Dinamarca e Grécia. Conquanto as moedas nacionais de cada país da Comunidade devam continuar a circular até o ano 2002, o Euro já pode ser utilizado através de cheques, cartões de crédito e lançamentos contábeis. ${ }^{11}$

No que toca à estrutura da Comunidade Européia, o órgão supremo de direção política é o Conselho Europeu, formado pelos chefes de governo dos Estados-Membros e pelo presidente da Comissão da Comunidade.

Segue-se o Conselho de Ministros, composto de um membro de cada país, cujo escopo é o de assegurar a coordenação das políticas econômicas dos Estados-Membros.

11. A taxa de sua conversão, na data em que foi lanç̧ado, assim se discrimina 1 euro $=6,55957$ francos franceses; I euro $=1,95583$ marco alemão; 1 euro $=40,3399$ francos belgas; 1 euro $=40,3399$ francos luxemburgueses; 1 euro $=0,787564$ libra irlandesa; 1 euro $=1.936,27$ liras italianas; 1 euro $=$ 166,386 pesetas espanholas; 1 euro $=2,20371$ florins holandeses; 1 euro $=13,7603$ shillings austríacos; 1 euro $=200,482$ escudos portugueses; 1 euro $=5,94573$ marcos finlandeses; 1 euro $=1,16675$ dólar; 1 euro $=0,705455$ libra esterlina; 1 euro $=132,800$ ienes. L'euro sur les fonts baptismaux, in Le Figaro, 01/01/1999, p. 3. 
Outro órgão de grande importância é o Parlamento Europeu, cujos membros se elegem democraticamente, com mandato de cinco anos e com a finalidade precípua de fiscalizar o funcionamento dos demais órgãos da Comunidade. Além disso, em consonância com o art. 189, do Tratado de Maastrich, tem competência para adotar, em conjunto com o Conselho Europeu, regulamentos, diretivas, decisões e recomendações. Compete-lhe, ainda, nomear provedor de Justiça, com poderes para receber queixas apresentadas por qualquer pessoa singular ou coletiva, com domicílio em qualquer dos Estados-Membros. O Parlamento Europeu menciona em Estrasburgo e se reúne anualmente.

O quarto órgão a ser considerado é a Comissão Européia, a que cabe velar pela aplicação das disposições do Tratado, bem como das medidas tomadas pelas restantes instituições comunitárias.

O quinto órgão a ser mencionado é a Corte Européia de Justiça, sediado em Luxemburgo e integrada por treze juízes nomeados pelo prazo de seis anos pelos membros da Comunidade. As funções primaciais da mencionada Corte são as de cassar toda e qualquer medida adotada no seio da Comunidade contrária ao Tratado em vigor e, por outro lado, as de interpretar a validade de tópicos da legislação comunitária questionados pelos tribunais nacionais.

Outras instituições integrantes da Comunidade são o Comitê Econômico e Social (CES), o Banco Europeu de Investimento (BEI), o Tribunal de Contas e o Fundo Social Europeu (vide arts. 123/127, do Tratado).

Merece realce especial o Comitê Econômico e Social, com sede em Bruxelas e integrado por representantes de três grupos: o dos trabalhadores, o dos empregados e o de categorias diferenciais, como a dos agricultores e consumidores.

Deriva do exposto que a Comunidade Européia, com o recente lançamento do Euro, inseriu-se na categoria mais avançada de integração econômica, que é a da união monetária.

4. Nafta

A sigla Nafta refere-se ao North American Free Trade Agreement, tratado de livre comércio firmado entre os EUA e o Canadá, o qual veio a ser subscrito também pelo México, em novembro de 1992.

No art. 102, do referido Tratado assim se especificam seus objetivos: "(a) eliminate barriers to trade in, and facilitate the cross-border movement of, 
goods and services between the territories of the Parties; (b) promote conditions of fair competition in the free trade area; (c) increase substantially investment opportunities in the territories of the Parties; (d) provide adequate and effective protection and enforcement of intellectual property rights in each Party's territory; (e) create effective procedures for the implementation and application of this Agreement, for its joint administration and for the resolution of disputes; and $(f)$ establish a framework for further trilateral, regional and multilateral cooperation to expand and enhance the benefits of this Agreement"

Como complemento do mesmo Tratado, há de se registrar a existência de acordo sobre cooperação no campo laboral, em que se explicitam os seguintes objetivos: "(a) improve working conditions and living stantards in each Party's territory; (b) promote, to the maximum extent possible, the labor principles set out in Annex 1; (c) encourage cooperation to promote innovation and rising levels of productivity and quality; (d) encourage publication and exchange of information, data development and coordination, and joint studies to enhance mutually beneficial understanding of the laws and institutions governing labor in each Party's territory; (e) pursue cooperative labor-related activities on the basis of mural benefit; $(f)$ promote compliance with, and effective enforcement by each Party of its labor law, and $(g)$ foster transparency in the administration of labor law"

\section{Mercosul}

O Mercosul resulta do Tratado de Assunção, subscrito pela Argentina, Brasil, Paraguai e Uruguai, no dia 26 de março de 1990. Seu objetivo declarado é a implantação de um mercado comum. Contudo, por não assegurar amplamente aos seus integrantes a livre circulação de mercadorias, pessoas, serviços e capitais, prefere Luiz Olavo Baptista caracterizá-lo como fórmula "sui generis" de mercado comum. $^{12}$

Com o advento do Protocolo de Ouro Preto, de 17 de dezembro de 1994, robusteceu-se a entidade, no que toca à realização de seus objetivos, sobretudo porque passou a possuir personalidade jurídica de Direito Internacional.

Os órgãos componentes de sua estrutura são os seguintes: I Conselho do Mercado Comum; II Grupo Mercado Comum; III Comissão de Comércio; IV

12. O Mercosul, suas instituições e ordenamento jurídico, São Paulo, LTr, 1998, p. 53. 
Comissão Parlamentar Conjunta; V Foro Consultivo Econômico e Social; VI Secretaria Administrativa.

O Conselho, composto pelos ministros das Relações Exteriores e pelos ministros da Economia dos Estados-Membros, constitui o órgão superior da entidade, incumbindo-lhe a condução política do processo de integração e a tomada de decisões para assegurar o cumprimento de seus objetivos.

O Grupo Mercado Comum, integrado por um representante de cada País-Membro, particulariza-se por constituir o órgão executivo do Mercosul.

Segue-se a Comissão de Comércio, também composta de quatro membros, cuja finalidade é a de dar assistência ao Grupo Mercado Comum.

O terceiro órgão a ser considerado é a Comissão Parlamentar, integrada por parlamentares representantes dos Estados-Membros e tendo como finalidade precípua despender esforços no sentido da harmonização das legislações dos mesmos países.

O quarto órgão do Mercosul é o Foro Consultivo Econômico e Social, integrado por igual número de representantes de cada Estado-Membro, com funções meramente consultivas.

Finalmente, há se considerar a Secretaria Administrativa, caracterizada como órgão de apoio operacional.

O Tratado de Assunção (v. art. 13) tanto quanto o Protocolo de Ouro Preto (v. art. 14) atribuíram ao Grupo Mercado Comum a prerrogativa de criarem subgrupos destinados ao melhor cumprimento de seus objetivos.

Em conformidade com a apontada previsão, criou-se o subgrupo 11 (hoje 10), atribuindo-se-lhe a incumbência de harmonizar os institutos jurídicolaborais, para o efeito de melhor se assegurar o processo de integração e a melhoria das condições de trabalho dos países pertencentes ao Mercosul.

Não há dúvida, portanto, de que a finalidade última do subgrupo 10 é a de buscar a melhoria das condições de trabalho, ${ }^{13}$ no âmbito da referida entidade. $E$ há de fazê-lo através da harmonização de institutos jurídico-laborais.

Sobre o sentido do vocábulo harmonização assim se manifesta João de Lima Teixeira Filho: "Sempre entendemos que harmonização não pode significar uniformidade de condições de trabalho, o que seria impossível de alcançar até

13. Entre as melhorias desejáveis aponta Amauri Mascaro Nascimento a necessidade de se facilitar a migração trabalhista. (Normas para Circulação de Trabalhadores no Mercosul, in Revista da Faculdade de Direito da USP, São Paulo, v. 90, 1995, p. 324). 
mesmo em razão da soberania interna de cada País-membro, das razões históricas de cada povo, da atuação dos sindicatos na fonte de produção de Direito do Trabalho etc. A harmonização tem o nítido sentido de redução, até onde possível for, das diferenças de tratamento que as legislações nacionais dispensem aos mais diversos assuntos" 14

Oscar Ermida Uriarte adota posição semelhante, preconizando a aplicabilidade de convenções da OIT e a adoção de uma Carta Social. ${ }^{15}$

No que toca às convenções da OIT, assim se manifesta: "La finalidad es la de crear un piso mínimo de protección de los derechos de los trabajadores de la región, válido en toda la dimensión geográfica de ésta. Es obvio que no se apunta a crear un Derecho supracional, sino a establecer, a través de la coincidencia de los conventos internacionales ratificados por cada pais, un Derecho internacional del trabajo común o uniforme por coincidencia" 16

No que concerne à adoção de Carta Social, Uriarte aduz as seguintes ponderações: "Lo teóricamente recomendable sería la hipótesis de máxima, lo mejor a que se podría aspirar en este momento (una Carta Social com normas jurídicas completas, eficaces y autoejecutables, controlada internacionalmente $y$ directamente aplicable por los tribunales nacionales). La hipótesis de mínima, en cambio, es decir, lo más modesto que se pudiera construir, sería una mera declaración de objetivos, propósitos o princípios, sin mecanismos de control" 17

Por outro lado, Floriano Corrêa Vaz da Silva, endossando palavras de Paulo de Tarso Silva, posiciona-se no sentido da necessidade de se democratizarem as relações de trabalho, no âmbito do Mercosul, ${ }^{18}$ opinião que se conjuga com a de

14. O Fator Trabalho no Mercado Comum do Sul, in Direito e Processo do Trabalho, coord. Mallet, Estêvão e Robertella, São Paulo, LTr, 1996.

15. Mercosur y Derecho Laboral, Montevideo, Fundacion Universitaria de Cultura Universitaria, 1996, pp. 17-19.

16. Idem, p. 17.

17. Características, contenido y eficacia de una eventual Carta Social del Mercosur, in ¿Una Carta Social del Mercosur?, Montevideo, Relasur, 1994, p. 27. Geraldo von Potobsky é mais enfático quanto à necessidade de uma Carta Social, como se depreende do texto abaixo reproduzido: " $L a$ aceptación del principio de una Carta Social para el Mercosur constituye un avance importante" (Naturaleza, contenido y eficacia de una eventual carta social del Mercosur". in ob. cit., "¿Una Carta Social..., p. 29).

18. Mercosul e Relações do Trabalho, São Paulo, Repertório IOB de Jurisprudência - Trabalhista e Previdenciário, $2^{\text {a }}$ quinzena de janeiro de 1995, n. 2/95, p. 28. 
Cássio Mesquita Barros Jr., ao afirmar que a eficácia plena de uma Carta Social depende da atuação da diplomacia dos Países-Membros do Mercosul. ${ }^{19}$

A partir dessa última observação, tudo indica que, ao invés da elaboração de uma Carta Social aparatosa e adstringente, que só viria exacerbar o caráter tutelar e farisaico das normas trabalhistas dos Países-Membros do Mercosul, o mais aconselhável seria a estimulação não-só de agentes diplomáticos senão também e, principalmente, de entidades sindicais, no sentido de se empenharem para assegurar a efetividade de direitos trabalhistas não através de benefícios outorgados por entidades estatais, mas por meio de condições negociadas, através de contratação coletiva de âmbito supranacional. ${ }^{20}$

Nesta altura, vale a pena trazer à tona a observação de Gérard LyonCaen, quanto à tendência do Direito do Trabalho "d'abandonner aux groupements d'employeurs et aux syndicats de salariés une large part d'autonomie dans l'établissement du contenu de leurs rapports" ${ }^{21}$ Por isso mesmo, no âmbito europeu, a Confederação Européia de Sindicatos mostra o seu destino cada vez mais ligado "à celui de la construction européene, dont elle est aujourd'hui l'un des principaux

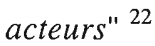

19. La proclamación de los derechos laborales fundamentales en el Mercosur in ob. cit., “¿Una Carta Social...' , p. 57.

20. No mesmo sentido Everaldo Gaspar Lopes, quando diz: "A este (o Estado) compete reduzir o grau de intervenção, estimula a livre negociação entre Capital e o Trabalho e assegurar que as regras da livre negociação sejam respeitadas garantindo a lisura do processo, o cumprimento do entendimento, bem como resguardando os direitos das partes." ( $O$ Mercosul e as relações de trabalho: relações individuais, relações coletivas, relações internacionais de trabalho, São Paulo, LTr, 1993, p. 33). Idêntica diretriz é sustentada por Marcelo Daniel Rolón, como se depreende da passagem abaixo: "Sí podría en cambio, reclamarse que se escuche a quiénes son los que realmente conocen las necesidades de cambio, y en especial se confie en ellos la promoción de la flexibilidad necesaria y útil. Me refiero concretamente a los actores de las relaciones laborales: empresas y trabajadores. Ellos son lo más aptos para producir los verdaderos cambios normativos que favorezcan las condiciones de trabajo necesarias para un mejor desarrollo del contrato de trabajo en las coindiciones actuales y, para ello, tienen disponible urra herramienta como la negociación colectiva y un instrumento como el convenio colectivo de trabajo para hacer efectivos esos cambios." (Flexibilizacion laboral: ¿Realidad o mito?, in Revista de Derecho del Mercosur, Buenos Aires, La Ley, 1997, p. 189).

21. Les relations de travail internationales, Paris, Liaisons, p. VII.

22. Portelli, Hugues, La Confédération Européenne des Syndicats, in Syndicalisme Dimensions Internationales, direction de Devin, Guillaume, La Garenne-Colombes, Édịtions Européennes Erames, 1990, p. 143. 
Na esfera do Mercosul, o que se preconiza é a abertura de espaço crescente para a atuação de entidades sindicais, ${ }^{23}$ como a ORIT, a CIOSL e outras, orientação a ser conjugada com o desmonte dos aparatos legislativos dos PaísesMembros do Mercosul, notadamente os do Brasil, do Paraguai e da Argentina. ${ }^{24}$

Tudo indica que esse constitui o melhor caminho para se dar efetividade à regra do parágrafo único, do art. $4^{\circ}$ da Constituição brasileira, "verbis": "A República Federativa do Brasil buscará a integração econômica, política, social e cultural dos povos da América Latina, visando à formação de uma comunidade latino-americana de nações"

São Paulo, janeiro de 1999.

23. Passos, Edésio, Mercosul - Relações do Trabalho, in Suplemento Trabalhista LTr n. 2/99, pp. 11-12. Vide também Cordeiro, António Menezes, Convenções colectivas de trabalho e alterações de circunstâncias, Lisboa, Lex, 1995, p. 36.

24. Lembra Oscar Ermida Uriarte a existência da Coordinadora de Centrales Sindicales del Cono Sur, existente desde antes da constituição do Mercosul e que ficou "notoriamente revitalizada por el desarrollo de la integración regional, convertiéndose en actor protagónico del espacio social del Mercosur." (Ob. cit., "Mercosur y Derecho Laboral", p. 32). 